\title{
The association of renal tubular acidosis and cyanotic congenital heart disease
}

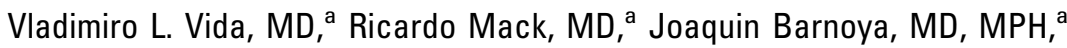 \\ Luis A. Larrazabal, MD, ${ }^{a}$ Randal Lou, MD, and \\ Aldo R. Castañeda, MD, PhD, ${ }^{a}$ Guatemala City, Guatemala
}

A

lthough late survival has been occasionally reported for patients with cyanotic congenital heart disease (CCHD), the complexity of the cardiac malformations and the complications of cyanosis prove often lifethreatening at an early age. ${ }^{1}$ It has been documented that chronic cyanosis affects renal glomerular structure and function, causing progressive glomerulopathy with eventual proteinuria., ${ }^{2,3}$ Adverse effects of chronic hypoxia on renal tubular function have been less frequently documented. ${ }^{4,5}$ Secondary renal tubular acidosis (sRTA) seems to be an acquired complication in patients with chronic cyanosis. The aim of this study was to evaluate the association of CCHD and renal tubular acidosis in a Guatemalan population.

\section{Patients and Methods}

Seventy-three of 110 patients with cyanosis (study group) with congenital heart disease were selected on the basis of an arterial oxygen saturation less than $80 \%$. In these patients, arterial $\mathrm{pH}$ and blood gas values, as well as plasma anion gap (PAG) and urinary anion gap

\footnotetext{
From the Department of Pediatric Cardiovascular Surgery, ${ }^{\mathrm{a}}$ UNICAR, and the Department of Nephrology, ${ }^{\mathrm{b}}$ Roosevelth National Hospital, Guatemala City, Guatemala.

Received for publication June 17, 2005; accepted for publication June 29, 2005.

Address for reprints: Vladimiro L. Vida, MD, Department of Pediatric Cardiovascular Surgery of Guatemala, UNICAR, 9 avenida, 8-00 Zona 11 Guatemala City, Guatemala CA (E-mail: vladimirovida@interfree.it).

J Thorac Cardiovasc Surg 2005;130:1466-7

$0022-5223 / \$ 30.00$

Copyright $\odot 2005$ by The American Association for Thoracic Surgery doi:10.1016/j.jtcvs.2005.06.040
}

(UAG) were measured to evaluate the origin of metabolic acidosis. Patients with diarrhea in the previous 15 days or receiving prolonged treatment with diuretics or laxatives were also excluded.

The diagnosis of sRTA should be suspected in all patients with a normal PAG and hyperchloremic metabolic acidosis. Differentiation of sRTA from other metabolic disorders is facilitated by the determination of the UAG. A UAG greater than 0 is indicative of an acidification defect at the distal tubular level (distal sRTA), whereas a UAG less than 0 suggests the presence of gastrointestinal or renal loss of bicarbonate (proximal sRTA). Fifty-six of the 73 patients included in the study (77\%) had metabolic acidosis (plasma bicarbonate $<22 \mathrm{mmol} / \mathrm{L}$ ); of these, $48(86 \%$ ) also had a normal PAG (sRTA group). The remaining 17 patients $(23 \%)$ had normal arterial $\mathrm{pH}$ and blood gas values (reference group). Metabolic acidosis originated from the distal renal tubule (UAG $>0$ ) in 39 patients $(81 \%$, distal sRTA) and from the proximal tubule (UAG $<0)$ in 9 patients $(19 \%$, proximal sRTA; Figure 1 and Table 1). Patients with distal renal tubular acidosis were significantly older than patients in the reference group $(P<.05)$. Differences in other variables analyzed in this study, such as patient nutritional status, altitude (meters above sea level), and renal function, were not significant.

Ten patients with sRTA who underwent surgical repair of their congenital heart disease with elimination of cyanosis (mean postoperative arterial oxygen saturation increased from $70.3 \% \pm 7.94 \%$ to $95.3 \% \pm 3.19 \%$ ) were evaluated at 48 postoperative hours. They had a normal arterial $\mathrm{pH}$ and blood gas profile.

TABLE 1. Age, arterial pH, blood gas values, and chemical data

\begin{tabular}{|c|c|c|c|c|}
\hline & $\begin{array}{c}\text { Reference } \\
\text { group }(n=17)\end{array}$ & $\begin{array}{c}\text { Distal sRTA } \\
(\mathrm{n}=39)\end{array}$ & $\begin{array}{l}\text { Proximal sRTA } \\
(\mathrm{n}=9)\end{array}$ & $P$ value* \\
\hline Age (mo, median and range) & $12(9-36)^{*, \dagger}$ & $24(12-96) \dagger$ & $24(12-36)^{*, \dagger}$ & .04 \\
\hline $\mathrm{pH}($ mean $\pm \mathrm{SD})$ & $7.38 \pm 0.02^{*}$ & $7.34 \pm 0.03 \dagger$ & $7.35 \pm 0.01 \dagger$ & .001 \\
\hline $\mathrm{PaO}_{2}(\mathrm{~mm} \mathrm{Hg}$, mean $\pm \mathrm{SD})$ & $48.09 \pm 13.10$ & $45.26 \pm 8.97$ & $41.15 \pm 5.38$ & .23 \\
\hline $\mathrm{PaCO}_{2}(\mathrm{~mm} \mathrm{Hg}$, mean $\pm \mathrm{SD})$ & $33.72 \pm 4.92^{*}$ & $27.76 \pm 3.86 \dagger$ & $28.02 \pm 2.36 \dagger$ & .001 \\
\hline Bicarbonate ion $(\mathrm{mmol} / \mathrm{L}$, mean $\pm \mathrm{SD})$ & $22.71 \pm 1.81^{*}$ & $17.82 \pm 1.39 \dagger$ & $18.54 \pm 0.65 \dagger$ & .001 \\
\hline Sodium ion $(\mathrm{mmol} / \mathrm{L}$, mean $\pm \mathrm{SD})$ & $139.64 \pm 3.14$ & $140.74 \pm 4.32$ & $138.44 \pm 2.87$ & .23 \\
\hline Potassium ion $(\mathrm{mmol} / \mathrm{L}$, mean $\pm \mathrm{SD})$ & $3.51 \pm 0.52^{*}$ & $3.06 \pm 0.58^{*}$ & $2.98 \pm 0.84^{*}$ & .03 \\
\hline Chloride ion $(\mathrm{mmol} / \mathrm{L}$, mean $\pm \mathrm{SD})$ & $101.20 \pm 4.01^{*}$ & $113.40 \pm 4.64 \dagger$ & $110.08 \pm 2.97 \dagger$ & .001 \\
\hline
\end{tabular}

*By analysis of variance. $†$ Values with different superscript letters are significantly different $(P<.05)$ in multiple comparison test (Tukey test). 


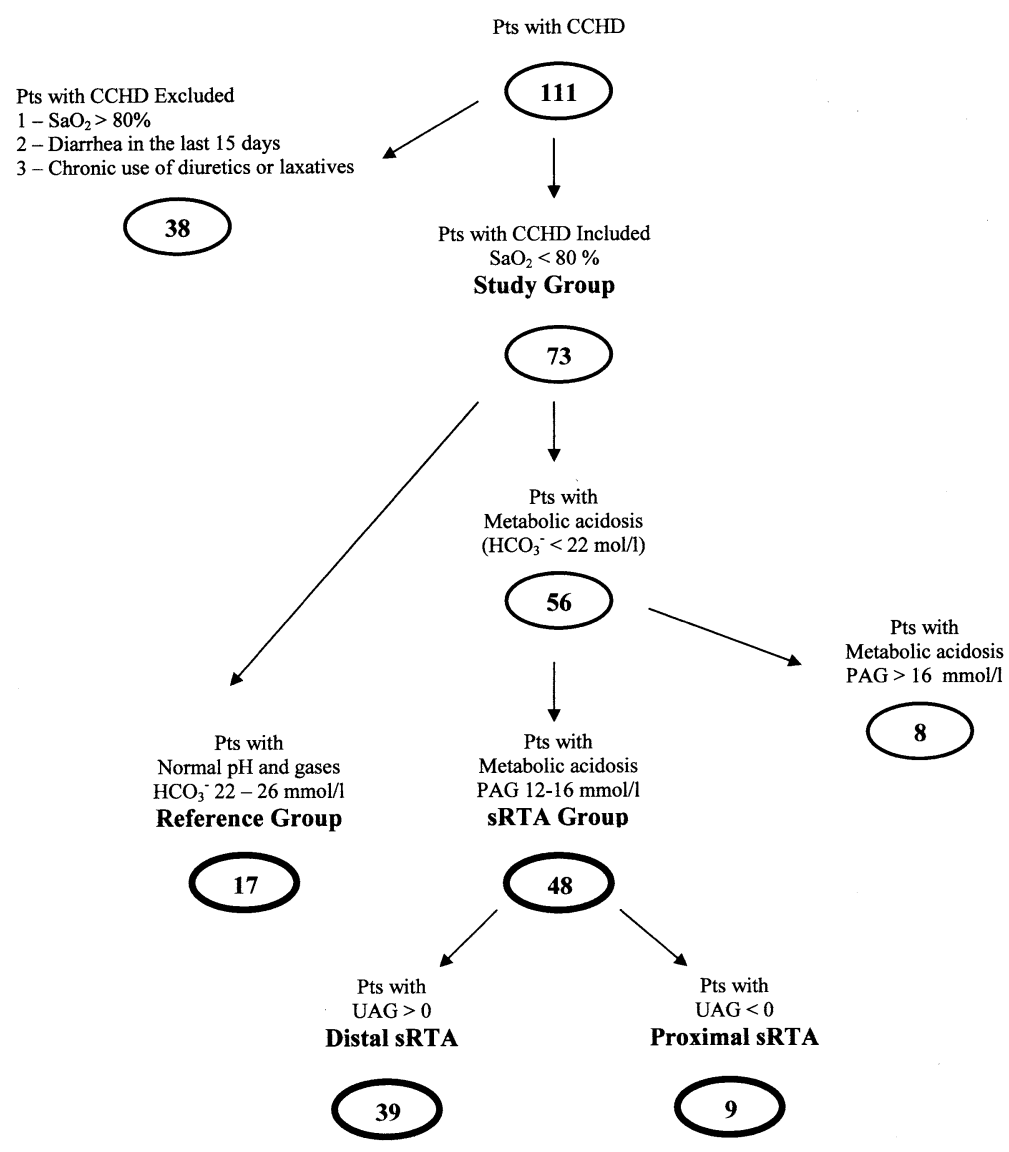

Figure 1. Nomogram of the study. $\mathrm{SaO}_{2}$, Arterial oxygen saturation; $\mathrm{HCO}_{3}{ }^{-}$, bicarbonate ion.

\section{Discussion}

In $66 \%$ of patients with CCHD included in the study, sRTA coexisted, with distal sRTA the predominant type (81\%). Unfortunately, we were unable to measure plasma lactate levels at our institution. However, the presence of a normal PAG hyperchloremic metabolic acidosis essentially excludes an increase in unmeasured anions as the possible cause. Neither could we measure urinary $\mathrm{pH}, \mathrm{PCO}_{2}$, and bicarbonate ion. Nevertheless, UAG proved useful in defining the inadequate acidification process in patients with metabolic acidosis and a normal PAG, after initial exclusion of other extrarenal causes (diarrhea or use of laxatives) known to alter blood levels of bicarbonate. Our data therefore clearly support the association of renal deficit of acidification as a result of chronic cyanosis.

The age of patients with CCHD seems to play a role in the development of distal sRTA. Patients with distal sRTA were significantly older (median age 24 months, range 12-96 months) than patients in the reference group (median age 12 months, range 9-36 months). However, the role of age requires further research.

Unlike previous reports, we found distal sRTA to be more common (81\%) than proximal sRTA (19\%). In all other series, ${ }^{4,5}$ proximal sRTA has been reported to be more common. Perhaps the high incidence of chronic malnutrition (62\%) and the large number of patients living 1500 meters above sea level (69\%) in our patient population contributed to this difference.

The prompt resolution of sRTA after surgical repair with normalization of arterial oxygen saturation, especially in the context of the significantly older age of patients with sRTA, seems to provide an additional argument in favor of early repair of CCHD. More studies and a larger number of patients are still necessary to elucidate the precise mechanisms responsible for sRTA in the presence of CCHD and its postoperative reversibility.

\section{References}

1. Oechslin EN, Harrison DA, Connelly MS, Webb GD, Siu SC. Mode of death in adults with congenital heart disease. Am J Cardiol. 2000;86: 1111-6.

2. Ingelfinger JR, Kissane JM, Robson AM. Glomerulomegaly in a patient with cyanotic congenital heart disease. Am J Dis Child. 1970;120:69-71.

3. Dittrich S, Haas NA, Buhrer C, Muller C, Dahnert I, Lange PE. Renal impairment in patients with long-standing cyanotic congenital heart disease. Acta Paediatr. 1998;87:949-54.

4. Rodriguez-Soriano J, Vallo A, Chouza M, Castillo G. Proximal renal tubular acidosis in the tetralogy of Fallot. Acta Paediatr Scand. 1975; 64:671-4.

5. Burlet A, Drukker A, Guignard JP. Renal function in cyanotic congenital heart disease. Nephron. 1999;81:296-300. 